\title{
SPORTIVE
}

https://dergipark.org.tr/tr/pub/sportive

\section{Orta Ergenlik Döneminde Uzaktan Eğitimle Beden Eğitimi ve Spor Dersi Alan Öğrencilerin Memnuniyet Düzeyinin Belirlenmesi}

\author{
Muhammed Yasin Büyükaslan
}

Necmettin Erbakan University,Ahmet Keleşoğlu Faculty of Education, Konya/Turkey

$\mathrm{Bu}$ çalışmanın amacı, orta ergenlik döneminde uzaktan eğitimle beden eğitimi ve spor dersi alan öğrencilerin uzaktan eğitim memnuniyet düzeyinin belirlenmesidir. Araştırmaya orta ergenlik dönemindeki Covid 19 salginından etkilenen ve bu yüzden uzaktan eğitim alan özel okul ve devlet okullarında öğrenim gören 14-17 yaşları arası 229 kız, 90 erkek toplam 319 öğrenci katılmıştır. Veri toplama aracı olarak betimsel tarama yönteminden yararlanılmıştır. Araştırmada kişisel bilgi formu ve Uzaktan Eğitimde Öğrenci Memnuniyet Ölçeği kullanılmıştır. Verilerin istatistiksel analizlerinde $\mathrm{P}<.05$ anlamlılık düzeyi kabul edilmiştir. Bulgular, 16-17 yaş grubundaki orta ergenlerin memnuniyet düzeyleri yüksek çıkarken, 14-15 yaş öğrencilerin memnuniyet düzeyleri düşük bulunmuştur. Cinsiyet değişkenine göre Kız öğrenciler erkek öğrencilere göre uzaktan eğitimle alınan beden eğitimi dersinden anlamlı bir fark ile memnundur. Bu durum beden eğitimi dersinde tutumları yüksek olan erkek öğrencilerin yüz yüze eğitim kadar etkili olmadığı düşüncesi ile açıklanabilir. Öğrencilerininternet kullanımı süresi memnuniyet düzeylerini etkilemiştir. Düzenli ve uzun süre internet kullanıma sahip öğrencilerin memnuniyet düzeyleri düşüktür. Bu durum internetin imkanlarının farkında olan orta ergenlerin beklenti yüksekliği ile açıklanabilir. Sonuçolarak uzaktan eğitimle beden eğitimle beden eğitimi dersi alan öğrencilerin birçok değişkene göre memnuniyet düzeyleri etkilenmiştir.İnternet erişimdüzeyi, öğrenci-öğrenci, öğrenci-öğretmen etkileşimi artırılmalıdır. Öğrencilerin sunuş yöntemi ile ders boyunca tek taraflı anlatıma maruz kalmamalı ilgi artıran ve öğrenciyi derse dahil eden etkinlikler sağlanmalıdır.

Anahtar kelimeler: Orta Ergenlik Dönemi, Uzaktan Eğitimi, Beden Eğitimi ve Spor Dersi

\section{Determination Of Middle Adolescence Students' Satisfaction Level Following Physical Education And Sports Lessons With Distance Education}

This study aims to determine middle adolescence students' satisfaction level in physical education and sports lessons with distance education. There were 229 girls and 90 boys, totally 319 students who were from private and public schools participated in this study. Their age range was from 14 to 17 years. The participants who are in middle adolescence aged followed distance education due to the 
Covid 19 pandemic. Survey method was used for study design. Data were collected with personal information form and Distance Education Student Satisfaction Scale. $\mathrm{P}<0.05$ was accepted as the significance level in all statistical analyzes. The results showed that the satisfaction levels of the middle adolescents in the 16-17 age group were high, while the 14-15 age group were low. According to the gender variable, female students are more satisfied with the physical education and sport lesson followed by distance education than those in male students. This can be explained that male students with high attitudes in physical education and sport lessons are not as effective as face-to-face education. Moreover, the duration of students' internet use affected their satisfaction levels. Students who use the internet regularly and a long time had low satisfaction levels. It can be explained as the high expectation of middle adolescents who are aware of the possibilities of the internet. As a result, students', who followed physical education lessons with distance education, the satisfaction levels were affected. Internet access level, student-student, and student-teacher interaction should be increased. According to findings, students should not be exposed to the one-sided narration during the lesson, and activities that increase interest and involve the student in the lesson should be provided.

Keywords: Middle Adolescence Period, Distance Education, Physical Education and Sports Lesson

\section{GİRİ̧̧}

Teknolojinin ve internetin gelişimi hayatımızda önemli değişikliklere yol açmıştır. Eğitim kavramı bu gelişmelerden etkilenmiş ve bilgiye erişimi kolaylaştıran uygulamalar, sosyal medya araçları, online ansiklopediler ortaya çıkmıştır. 2020 Aralık ayında başlayan Covid-19 salgını nedeniyle uzaktan eğitim kavramı önemini daha da arttırmıştır. Uzaktan Eğitim kavramı yaygın eğitim metodu halini almış, insanlar mekanlara ya da belirli zamanlara kalmadan çevrimiçi ya da videolar üzerinden eğitim alabilmiştir (Kapıdere vd., 2011).

Çeşitli nedenlerle örgün eğitime erişemeyen öğrenciler için tasarlanan uzaktan eğitim; öğretmenler ve öğrencilerin çevrimiçi ortamlarda bir araya geldiği, aktif öğrenme sağlanan, görev ve sorumlulukların, bilgilerin paylaşımının sağlandığ çevrimiçi eğitim alanıdır. Dersin planlanması, öğrencilerin aktif katılımı sağlanması, öğrenci merkezli olması ve problem çözme odaklı olması önemlidir (Kapıdere vd., 2011; Türkoğlu, 2003). Uzaktan eğitim platformlarına TV, tablet, dizüstü, telefon gibi araçlarla erişim sağlanabilmektedir.

Uzaktan eğitimdeki esnek yapı, okulların kapalı olduğu salgın döneminde eğitimin aksamaması adına kolaylık sağlamıştır. Tam kapanma dönemlerinde eğitimin aksamaması adına Millî Eğitim Bakanlığı uzaktan eğitim sürecini Türkiye Radyo Televizyon Kurumu (TRT) ve Eğitim Bilişim Ağı (EBA) üzerinden başlatılmıştır. (MEB, 2020) $\mathrm{Bu}$ sürece göre TV üzerinden haftalık programlar belirlenmiş telafi eğitimleri ve yeni konular öğrencilere aktarılmıştır. EBA üzerinden ise internet erişimi sağlayan öğrenciler sıra arkadaşları birlikte çevrimiçi sınıflarında okullarındaki öğretmenleri ile uzaktan eğitimlere devam edilmiştir. 
Uzaktan eğitim süreci ülkemizde ve dünyada kusuruz ilerlememektedir. En önemli sorunlardan biri öğrenci ve öğretmenlerin erişimi olarak karşımıza çıkmaktadır (Moreno ve Gortazar, 2020). Eğitimde eşitsizlik yaşanması muhtemel olarak görülmektedir. Teknik bakımın sürekli yapıldığı, zaman zaman kesintilere uğradığı bilinmektedir. Yaşanan teknik ve donanımsal sorunların haricinde sosyal ve gelişimsel problemler ortaya çlkmıştır (Sirem ve Baş, 2020). Beden eğitimi ve spor, müzik, görsel sanatlar gibi öğretmen öğrenci etkileşimin yoğun olduğu yetenek keşfi ve teknik beceri aktarımı gerektiren derslerde çevrimiçi ortamlar yetersiz kalabilmektedir.

Beden eğitimi ve spor dersi, öğrencilerin fiziksel ve zihinsel olarak öğrencileri hayata hazırlar ve temel spor branşlarını öğretir. Sedanter yaşamdan kaçınmanın yollarını gösterir. Öğrencilerin gelişiminde beden eğitimi ve spor dersi kalıcı izler bırakır. Orta ergenlik dönemdeki öğrencilerin uzaktan beden eğitimi ve spor dersi alması fiziksel, zihinsel gelişimlerini önemli ölçüde etkileyecektir. Uzun ve Boyalı (2020)'ya göre fiziksel ve psikolojik gelişimin yoğun olduğu orta ergenlik dönemi 14-17 yaşları arasında kabul edilir.

Uzaktan eğitimle öğrencilerin beden eğitimi ve spor dersinden ne kadar memnun oldukları internete erişim oranları, düzenli katılım oranları, merak konusudur. $\mathrm{Bu}$ çalışmanın amacı; orta ergenlik döneminde uzaktan eğitimle beden eğitimi ve spor dersi alan öğrencilerin uzaktan eğitim memnuniyet düzeyinin belirlenmesidir.

\section{YÖNTEM}

\section{Araştırma Grubu}

Araştırmaya orta ergenlik dönemindeki Covid 19 salgınından etkilenen ve bu yüzden uzaktan eğitim alan, özel okul ve devlet okullarında öğrenim gören 14-17 yaşları arası $229 \mathrm{kız} 90$ erkek toplam 319 öğrenci katılmıştır. Araştırmaya katılan öğrenciler uygun örneklem yöntemi ile belirlenmiştir. Gönüllü olan öğrenciler araştırmaya dahil edilmiş ve hiçbir öğrenci araştırmaya katılması için zorlanmamıştır. (Creswell vd., 2007).

\section{Veri toplama aracı}

Veri toplama aracı olarak anket yönteminden yararlanılmıştır. Araştırmada kişisel bilgi formu ile Uzaktan Eğitimde Öğrenci Memnuniyet Ölçeği kullanılmıştır (Ilgaz, 2008).Necmettin Erbakan Üniversitesi 16.04.2021 tarih ve 2021/247 sayll Etik Kurul onayı alınmıştır.

Öğrencilerin uzaktan eğitimle ilgili derse olan memnuniyetini belirlemek, derse katılımları ve dersin ne kadar etkin olduğunu ölçmek amacıyla Uzaktan Eğitimde Öğrenci Memnuniyet Ölçeği kullanılmıştır. Değerlendirmede 34 soru kullanılmıştır. Ölçek 7'li likert tipinde olup öğrenciler maddelere "Hiç Katılmıyorum=1" ve "Tamamen Katılıyorum=7" kriterlerine göre 1'den 7'ye kadar bir puan vermişlerdir. 


\section{Verilerin Analizi}

Araştırmada elde edilen verilerin analizinde SPSS 23 paket programı kullanılmıştır. Normallik analizi yapılmış olup iki bağımsız değişken arasında bağımsız örneklem grubu $\mathrm{T}$ testi yapılmıştır. İkiden fazla değişkenler arasında tek yönlü varyans analizi ANOVA testi yapılmıştır. Normal dağılım göstermeyen yaş için MannWhitney U testi yapılmış, yüzdelik, frekans gibi değerleri alınmıştır.

\section{BULGULAR}

Tablo1. Araştırma değişkenlerine ait yüzdelik ve frekans tablosu

\begin{tabular}{llll}
\hline & Değişkenler & n & \% \\
\hline Cinsiyet & Kız & 229 & 71.8 \\
& Erkek & 90 & 28.2 \\
\hline Yaş & 14 -15 Yaş & 128 & 40.1 \\
& $16-17$ Yaş & 191 & 59.9 \\
\hline Internet kullanımı & Düzenli & 224 & 70.2 \\
& Düzensiz & 29 & 9.1 \\
& Kısmen Düzenli & 66 & 20.7 \\
\hline \multirow{2}{*}{ Internet kullanma süresi } & $1-2$ yıl & 137 & 42.9 \\
& $3-4$ yıl & 59 & 18.5 \\
& 4 yıl ve üzeri & 123 & 38.6 \\
\hline
\end{tabular}

Araştırmaya katılan öğrencilerin 229'u kadın ve 90’ı erkektir (\%71.8 ve \%28.2). Yaş gruplarına göre 14-15 yaş 128 kişi, 16-17 yaş 191 kişidir. (\%40.1, \%59.9). İnternet erişimi açısından yapılan değerlendirmede düzenli 224 kişi, düzensiz 29 kişi ve kısmen düzenli 66 kişi (\%70.2\%9.1, \%20.7) olduğu belirlenmiştir.

Internet kullanma süresi açısından ise katılımcıların 1-2 yıl 137 kişi, 3-4 yıl 59 kişi ve 4 yıl ve üzeri ise 123 kişiden oluşmaktadır (\%42.9, \%18.5, \%38.6).

Tablo 2. Araştırmaya yönelik olarak tanımlayıcı istatistik değerleri ve normal dağılım göstergeleri

\begin{tabular}{lccccc}
\hline Değişkenler & $\mathbf{n}$ & $\mathbf{x}$ & SS & skewness & kurtisos \\
\hline Cinsiyetiniz & 319 & 1.28 & .45 & .97 & -1.06 \\
Yaşınız & 319 & 1.63 & 2.21 & 3.81 & 14.22 \\
Internete Erişim & 319 & 1.50 & .82 & 1.14 & -.53 \\
Bilgisayar Kullanma Süreniz & 319 & 1.96 & .90 & .09 & -1.77 \\
\hline
\end{tabular}

Tablo 2`de araştırmaya yönelik olarak tanımlayıcı istatistik değerleri ve normal dağılım göstergeleri verilmiştir. Tabloya göre yaş değişkeninin normal dağılım göstermediği ortaya çıkmıştır. Çarpıklık ve basıklık değerlerinin -2 ile +2 değerlerinden fazla olmasıyla açıklanmaktadır (George ve Mallery, 2010). Yaş değişkenine parametrik olmayan analiz tekniği uygulanırken diğer değişkenlere parametrik analiz teknikleri uygulanmıştır. 
Büyükaslan MY. (2021) Orta Ergenlik Döneminde Uzaktan Eğitimle Beden Eğitimi ve Spor Dersi Alan Öğrencilerin Memnuniyet Düzeyinin Belirlenmesi.SPORTIVE, 4(2), 24-30.

Tablo 3. Cinsiyet değişkenine göre memnuniyet ölçeğinden alınan puanların karşılaştırılması

\begin{tabular}{clccccc}
\hline & & $N$ & $X$ & $S s$ & $\boldsymbol{t}$ & $\boldsymbol{P}$ \\
\hline \multirow{3}{*}{ Cinsiyet } & Kiz & 199 & 4.96 & 1.41 & -.83 & $\mathbf{. 4 1}^{*}$ \\
& Erkek & 83 & 5.09 & 1.08 & & \\
\hline
\end{tabular}

Tablo 3`ye göre kı ve erkek katılımcıların memnuniyet düzeylerinin karşılaştırılması sonucunda değişkenler arasında anlamlı farklılıklara rastlanmıştır. $(\mathrm{p}<.05)$.

Tablo 4. Yaş değişkenine göre memnuniyet düzeylerinin karşılaştırılması

\begin{tabular}{lllllll}
\hline & & $\mathbf{n}$ & $\mathbf{X}$ & $\mathbf{u}$ & $\mathbf{z}$ & $\mathbf{p}$ \\
\hline Yaş & $14-15$ yaş & 114 & 164.61 & 6941.00 & 3.92 & $.00^{*}$ \\
& $16-17$ yaş & 168 & 125.82 & & & \\
\hline \multicolumn{7}{c}{282} \\
\hline
\end{tabular}

Tablo 4`e göre memnuniyet düzeylerinin karşılaştırılması sonucunda 14-15 ile 16-17 yaş grubu öğrencilerin memnuniyet düzeyleri arasında anlamlı farklılıklar görülmüştür. $(p<.05)$.

Tablo 5. Araştırmaya katılan öğrencilerin internete erişim durumlarına göre memnuniyet düzeylerinin değerlendirilmesi.

\begin{tabular}{llllll}
\hline & $\boldsymbol{N}$ & $\boldsymbol{X}$ & $\boldsymbol{S S}$ & $\boldsymbol{F}$ & $\mathbf{p}$ \\
\hline Düzenli & 200 & 5.11 & 1.21 & & \\
Düzensiz & 26 & 4.41 & 1.49 & 3.48 & $\mathbf{. 0 3}^{*}$ \\
Kısmen Düzenli & 56 & 4.90 & 1.56 & & \\
\hline Toplam & 282 & 5.00 & 1.33 & & \\
\hline
\end{tabular}

Tablo 5`e göre araştırmaya katılan öğrencilerin internete erişim durumlarına göre memnuniyet düzeylerinin değerlendirilmesi sonucunda değişkenler arasında anlamlı farklılık tespit edilmiştir. $(\mathrm{p}<.05)$.

Tablo 6. Araştırmaya katılan öğrencilerin internete bağlanma sürelerine göre memnuniyet düzeylerinin değerlendirilmesi

\begin{tabular}{llllll}
\hline & $\mathbf{n}$ & $\mathbf{x}$ & $\mathbf{S S}$ & $\mathbf{f}$ & $\mathbf{p}$ \\
\hline 1-2 yıl & 124 & 5.05 & 1.30 & & \\
3-4 yll & 54 & 5.44 & 1.08 & 5.79 & $\mathbf{. 0 0 *}$ \\
5 yll ve üzeri & 104 & 4.71 & 1.41 & & \\
\hline Total & 282 & 5.00 & 1.33 & & \\
\hline
\end{tabular}

Tablo 6’ya göre araştırmaya katılan öğrencilerin internete erişim sürelerine göre memnuniyet düzeylerinin değerlendirilmesi sonucunda değişkenler arasında anlamlı farklılık tespit edilmiştir. $(\mathrm{p}<.05)$. 


\section{TARTIŞMA ve SONUÇ}

$\mathrm{Bu}$ çalışma orta ergenlik döneminde uzaktan eğitimle beden eğitimi ve spor dersi alan öğrencilerin uzaktan eğitim memnuniyet düzeyinin belirlenmesi amacıyla yapılmıştır. Bulgulara göre uzaktan eğitim memnuniyeti cinsiyet açısından farklılık göstermemektedir. Çalışmamızla paralel olmasa da Akandere ve arkadaşları (2010) ortaokul öğrencilerinin beden eğitimi dersine yönelik tutumları ile akademik başarıları arasındaki ilişkiyi incelemişlerdir. Bulgulara göre erkek ortaokul öğrencilerinin beden eğitimi dersine yönelik tutumları kız öğrencilere göre anlamlı düzeyde yüksek bulunmuştur. Lise öğrencilerinin beden eğitimi dersine yönelik tutumları literatürde incelenmiş ve erkek öğrencilerin daha yüksek tutuma sahip olduklarını belirlemişlerdir (Akıncı ve ark., 2020; Pepe ve Özkurt, 2016). Çalışmamızla benzer olmasa da literatürdeki çalışmalarda elde edilen bulguların farklı olmasının nedenleri olarak farklı örneklem sayısı ve kullanılan ölçek farklılıkları örnek gösterilebilir.

Öğrencilerin yaş değişkenine bakıldığında 14-15 yaş ile 16-17 yaş arasında anlamlı farklılık belirlenmiş̧tir. 16-17 yaş öğrenciler uzaktan eğitim ile beden eğitimi ve spor dersinde memnuniyet düzeyleri yüksektir. Öğrencilerin uzaktan eğitim memnuniyetini artıran unsurlar arasında öğrenci-öğrenci ve öğrenci-öğretmen etkileşimidir (Eygü \& Karaman, 2013). Pandemi sürecinde ortaöğretime başlayan öğrencilerin aynı fiziksel ortamda bulunmadıkları için tarafların etkileşim düzeyi daha kısıtlı olacaktır. Bu kısıtlık durumunun memnuniyet düzeylerini etkilediği düşünülmektedir. Bu durum 14-15 yaşındaki orta ergenliğe giren bireylerin beden eğitimi ve spor ders saatlerinin yüksek olduğu 9. ve 10. sinıflarda uzaktan eğitimin yetersiz kaldı söylenebilir.

İnterneti düzenli kullanım oranlarına göre bakıldığında öğrencilerin \%70’i düzenli internete sahiptir. Bu oran uzaktan eğitimde en önemli nokta olan erişimin halen istenilen düzeyde olmadığını göstermektedir. Uzaktan eğitimin etkili olması için internet probleminin çözülmüş olması gerekir (Doğrukök vd., 2021). Düzenli kullanıma sahip öğrencilerde memnuniyet düzeyi kısmen düzenli ve düzensiz internete sahip olanların oranlarından daha düşüktür. Düzenli internet kullanıma sahip öğrencilerin uzaktan eğitim memnuniyet düzeylerinin düşük olmasının nedeni uzaktan eğitim beklentilerinin daha yüksek olması nedeniyle açıklanabilir.

Araştırmacıların Katkı Oranı Beyanı: Araştırma Dizaynı- M. Yasin Büyükaslan; İstatistik analiz- M. Yasin Büyükaslan; Makalenin hazırlanması M. Yasin Büyükaslan; Verilerin Toplanması- M. Yasin Büyükaslan tarafından gerçekleştirilmiş̧ir. 
Büyükaslan MY. (2021) Orta Ergenlik Döneminde Uzaktan Eğitimle Beden Eğitimi ve Spor Dersi Alan Öğrencilerin Memnuniyet Düzeyinin Belirlenmesi.SPORTIVE, 4(2), 24-30.

Çıkar Çatışması: Çalışma kapsamında herhangi bir kişisel ve finansal çıkar çatışması bulunmamaktadır.

\section{Etik Kurul İzni ile ilgili Bilgiler}

Kurul Adı: Necmettin Erbakan Üniversitesi Etik Kurulu

Tarih:16/04/2021

Sayı/Karar No: 04/291

\section{KAYNAKLAR}

Akandere, M., Özyalvaç, N. T., \& Duman, S. (2010). Ortaöğretim Öğrencilerinin Beden Eğitimi Dersine Yönelik Tutumları İle Akademik Başarı Motivasyonlarının İncelenmesi Konya Anadolu Lisesi Örneği. Selçuk Üniversitesi Sosyal Bilimler Enstitüsü Dergisi(24), 1-10.

Akıncı, A. Y., Türkay, İ. b. K., Arısoy, A., \& Deniz, C. (2020). Lise Öğrencilerinin Beden Eğitimi Dersi Tutumlarının Bazı Değişkenlere Göre İncelenmesi (Isparta Örneği). Çanakkale Onsekiz Mart Üniversitesi Spor Bilimleri Dergisi, 3(3), 53-62.

Creswell, J. W., Hanson, W. E., Clark Plano, V. L., \& Morales, A. (2007). Qualitative Research Designs: Selection And Implementation.The Counseling Psychologist, 35(2), 236-264.

Doğrukök, B., Kurnaz, A., Barışık, C. Ş., \& Kaynar, H. Lise Öğrencilerinin Uzaktan Ĕgitime İlişkin Algilarinin Farkli Değişkenler Açisindan Değerlendirilmesi. Stratejik ve Sosyal Araştırmalar Dergisi, 5(1), 146-169.

Eygü, H., \& Karaman, S. (2013). Uzaktan Eğitim Öğrencilerinin Memnuniyet Algıları Üzerine Bir Araştırma.Kırıkkale Üniversitesi Sosyal Bilimler Dergisi, 3(1), 36-59.

George, D., ve Mallery, M. (2010). SPSS for Windows Step by Step: A Simple Guide and Reference, 17.0 update (10a ed.) Boston: Pearson

Ilgaz, H. (2008). Uzaktan Eğitimde Teknoloji Kabulünün Ve Topluluk Hissinin Öğrenen Memnuniyetine Katkisi. Hacettepe Üniversitesi,

Kapıdere, M., Altıparmak, M., \& Kurt, İ. D. (2011). E-Öğrenme Ve Uzaktan Eğitimde Açik Kaynak Kodlu Öğrenme Yönetim Sistemleri.

Moreno, J. M., \& Gortazar, L. (2020). Schools' readiness for digital learning in the eyes of principals. An analysis from PISA 2018 and its implications for the COVID19 (Coronavirus) crisis response. Education for Development Blog, Washington, DC: The World Bank.

Pepe, K., \& Özkurt, R. (2016). Kadın Ve Erkek Lise Öğrencilerinin Beden Eğitimi Ve Spor Dersine Yönelik Tutumlarının Araştırılması.Uluslararası Spor Egzersiz ve Antrenman Bilimi Dergisi, 2(3), 93-101.

Sirem, Ö., \& Baş, Ö. (2020). Okuma Güçlüğü Olan İlkokul Öğrencilerinin Covid-19 Sürecinde Uzaktan Eğitim Deneyimleri. Electronic Turkish Studies, 15(4).

Türkoğlu, R. (2003).İnternet Tabanlı Uzaktan Eğitim Programı Geliştirme Süreçleri.The Turkish Online Journal of Educational Technology-TOJET, 2:(3), 116.

Uzun, A.,\& Boyalı, E. (2020). Ergenlik Dönemleri ve Spor. Çocuk ve Egzersiz. 